\title{
Role of male partners in the prevention of mother-to-child HIV transmission
}

This article was published in the following Dove Press journal:

Research and Reports in Neonatology

23 July 2014

Number of times this article has been viewed

\author{
Alfred Osoti ${ }^{1-3}$ \\ Hannah $\mathrm{Han}^{4}$ \\ John Kinuthia ${ }^{1,5}$ \\ Carey Farquhar $3,4,6$ \\ 'Department of Obstetrics and \\ Gynecology, University of Nairobi, \\ Nairobi, Kenya; ${ }^{2}$ Department of \\ Obstetrics and Gynecology, AIC \\ Kijabe Hospital, Kijabe, Kenya; \\ ${ }^{3}$ Department of Epidemiology, \\ ${ }^{4}$ Department of Global Health, \\ University of Washington, Seattle, \\ USA; ${ }^{5}$ Department of Obstetrics \\ and Gynecology, Kenyatta National \\ Hospital, Nairobi, Kenya; 'Department \\ of Medicine, University of Washington, \\ Seattle, USA
}

\begin{abstract}
There is emerging evidence that in resource-limited settings with a high human immunodeficiency virus (HIV) burden, male partner involvement in prevention of mother-tochild HIV transmission (PMTCT) is associated with improved uptake of effective interventions and infant HIV-free survival. There is also increasing evidence that male partner involvement positively impacts non-HIV related outcomes, such as skilled attendance at delivery, exclusive breastfeeding, uptake of effective contraceptives, and infant immunizations. Despite these associations, male partner involvement remains low, especially when offered in the standard antenatal clinic setting. In this review we explore strategies for improving rates of antenatal male partner HIV testing and argue that the role of male partners in PMTCT must evolve from one of support for HIV-infected pregnant and breastfeeding women to one of comprehensive engagement in prevention of primary HIV acquisition, avoidance of unintended pregnancies, and improved HIV-related care and treatment for the HIV-infected and uninfected women, their partners, and children. Involving men in all components of PMTCT has potential to contribute substantially to achieving virtual elimination of mother-to-child HIV transmission; promoting partner-friendly programs and policies, as well as pursuing research into numerous gaps in knowledge identified in this review, will help drive this process.
\end{abstract}

Keywords: male involvement, limited-resource settings, maternal child health

\section{Introduction}

To achieve elimination of new human immunodeficiency virus (HIV) infections among children and a 50\% reduction in acquired immunodeficiency syndrome (AIDS)-related maternal deaths by $2015,{ }^{1}$ the World Health Organization (WHO) is promoting a comprehensive approach to the prevention of mother-to-child HIV transmission (PMTCT), which includes primary prevention of HIV infection among women of childbearing age (Prong 1), preventing unintended pregnancies among women living with HIV (Prong 2), preventing HIV transmission from a woman living with HIV to her infant (Prong 3), and providing treatment, care, and support to women living with HIV, their children, and families (Prong 4). ${ }^{2}$ In low resource settings with high mother-to-child HIV transmission (MTCT) rates, male partners must be considered as part of this approach because they often make key decisions that affect the health of women and their children, including use of PMTCT interventions, family planning, and access to medical care. ${ }^{3,4}$ Thus, male involvement in the context of PMTCT has evolved from seeking male partner support for HIV-infected pregnant and breastfeeding women to the comprehensive engagement of men in interventions that prevent HIV-uninfected female partners from acquiring HIV, reduce
Correspondence: Carey Farquhar International AIDS Research and Training Program, University of Washington, 325 9th Avenue Box 359909, Seattle, WA 98104, USA

Tel +l 2065434278

Fax +I 2065434818

Email cfarq@uw.edu submit your manuscript | www.dovepress.com Dovepress
Research and Reports in Neonatology 2014:4 I3 I-I38

(c) (i) (5) 2014 0soti et al. This work is published by Dove Medical Press Limited, and licensed under Creative Commons Attribution - Non Commercial (unported, v3.0) License. The full terms of the License are available at http://creativecommons.org/licenses/by-nc/3.0/. Non-commercial uses of the work are permitted without any further permission from Dove Medical Press Limited, provided the work is properly attributed. Permissions beyond the scope of the License are administered by Dove Medical Press Limited. Information on
how to request permission may be found at: http://www.dovepress.com/permissions.php 
unintended pregnancies, and improve care, treatment, and support for the HIV-infected male partner and the entire family (Figure 1). ${ }^{2}$ We conducted this review to evaluate the role of male partners in comprehensive PMTCT and to examine the challenges and strategies used to involve male partners during pregnancy and breastfeeding.

\section{Low rates of male partner involvement in PMTCT and antenatal care}

In most studies, male involvement in PMTCT activities and antenatal care (ANC) has been estimated as or equated to the proportion of male partners who undergo HIV testing and counseling (HTC) when their female partners are pregnant or breastfeeding. ${ }^{5}$ However, using HIV testing in the ANC as the marker of male engagement does not capture men's attitudes or support for PMTCT, both of which are likely to have greater impact on maternal and child health outcomes. Attempts have therefore been made to define the degree of male partner involvement, including one study in which a score was assigned based on whether the male partner: 1) accompanied his wife during ANC services; 2) knew the ANC schedule; 3) discussed ANC interventions with his female partner; 4) paid for ANC fees; 5) knew what happened at the ANC; and 6) used condoms with his partner during the current pregnancy. In this grading system, scores between 0 and 3 were considered weak male involvement and scores of 4 and above were considered as high male involvement. ${ }^{6}$ While this system may more accurately reflect male involvement, it has not been validated and most efforts to engage men in PMTCT have focused on increasing the proportion of male partners who undergo individual or couple HTC during the pregnancy or breastfeeding periods of their female partners. ${ }^{7}$

Using this surrogate measure, male involvement in PMTCT activities and reproductive health remains extremely low in regions hardest hit by the HIV epidemic. Studies across sub-Saharan Africa report rates of male partner HTC ranging from 5\%-33\%, with the majority reporting that less than one in five men get HIV tested during their partner's pregnancy (Figure 2). ${ }^{5-20}$ A retrospective evaluation of PMTCT medical records in a referral hospital in Uganda showed that less than 5\% of male partners underwent HTC. ${ }^{21}$ Another randomized trial in Uganda that offered a written invitation or information note resulted in only $15 \%$ male partner testing. ${ }^{11}$ In Kenya, uptake of male partner HTC was also approximately $15 \%$, despite promotion of a male-friendly environment for individual or couple HIV testing, ${ }^{5,13,14}$ and in a randomized clinical trial that offered couple versus individual HIV counseling and testing for couples in Tanzania, only $16 \%$ of men underwent couple HTC. ${ }^{15}$ In Southern Africa, rates have been similar, with one study conducted among HIV-positive women in a district hospital in Malawi reporting male partner involvement of $14 \% .^{22}$ Higher rates have been reported in South Africa where one in three male partners underwent HTC in the antenatal clinic following extensive community mobilization and sensitization. ${ }^{9}$ The increase in male testing rates observed in South Africa with extensive community outreach and sensitization is encouraging but leaves considerable room for improvement in employing other strategies, some of which are now under investigation.

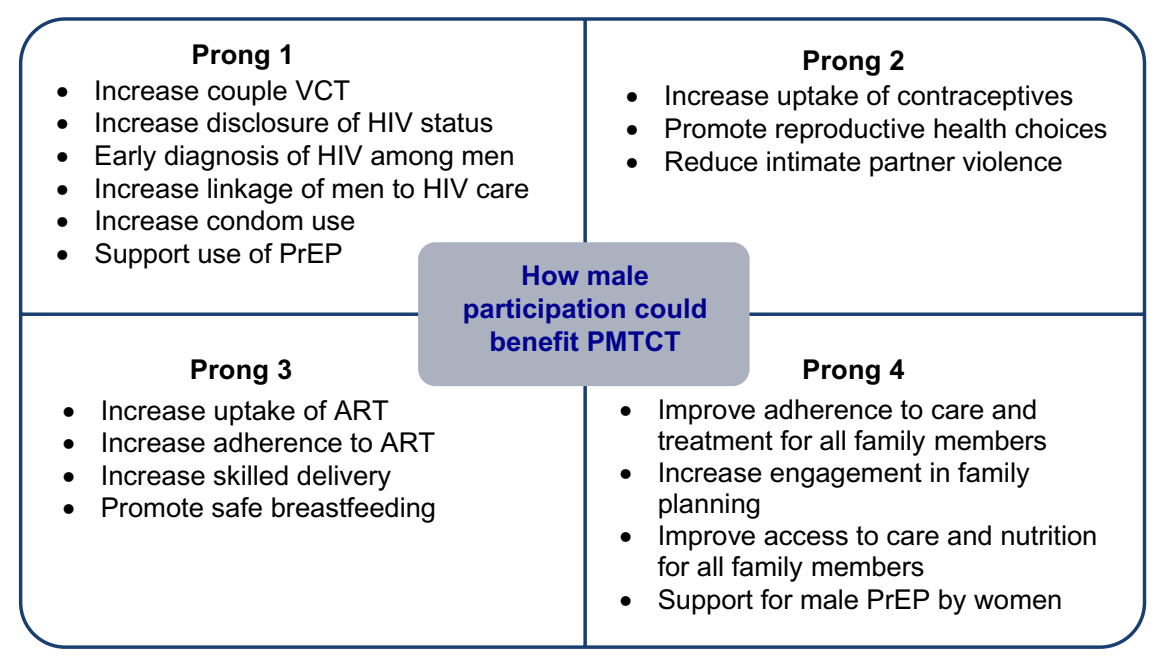

Prong 1: Prevention of
HIV infection among
women.
Prong 2: Prevention of
unintended pregnancies
among HIV+ women.
Prong 3: Prevention of
vertical transmission.
Prong 4: Treatment,
care and support for
HIV+ mothers, children
and families.

Figure I Benefits of male partner participation in PMTCT efforts within the WHO comprehensive four-pronged approach to virtual elimination of vertical HIV transmission. Abbreviations: ART, antiretroviral therapy; HIV, human immunodeficiency virus; HIV+, human-immunodeficiency-virus positive; PMTCT, prevention of mother-to-child HIV transmission; PrEP, preexposure prophylaxis; VCT, Voluntary counseling and HIV testing; WHO, World Health Organization. 


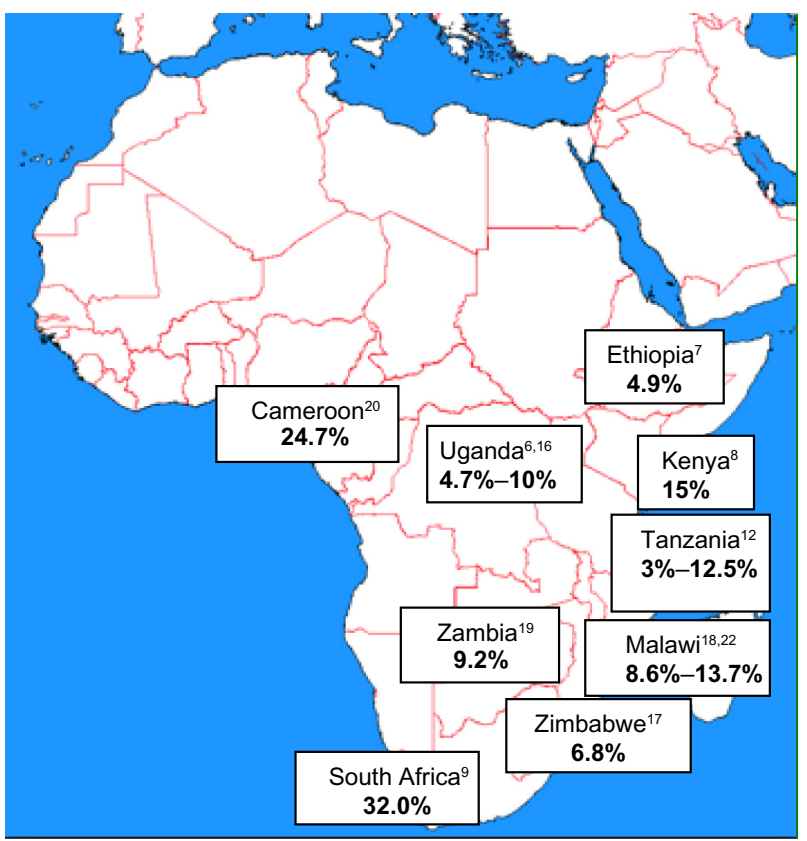

Figure 2 Proportion of male partners in sub-Saharan Africa accessing HIV testing in antenatal care clinics.

\section{Strategies to enhance male partner involvement}

Over the last decade, different strategies have been used to increase male partner involvement in PMTCT during pregnancy and the breastfeeding period, most of which have been clinic based. These have included: reorganizing ANC clinic operations to provide male HTC during weekends or evenings; use of mass media advertisements and posters promoting male testing; incentives to women who attend ANC with their partners, such as fast tracking of ANC clinic procedures; invitations to male partners to attend ANC using oral communications or written notes; and couple oriented counseling in place of routine antenatal HIV testing..$^{9,10}$ Overall, these strategies have had limited success across different settings, prompting a shift to non-clinic based efforts to increase male partner testing.

Several innovative approaches to HIV testing of men outside the clinic have been studied and have had encouraging, but mixed, results. A randomized clinical trial in the Democratic Republic of the Congo found that male partners of pregnant women who were attending a maternity unit were significantly more likely to be tested in bar-based voluntary counseling and testing (VCT) sites when compared with testing in a clinic-based VCT ( $26 \%$ versus $18 \% ; P<0.001)$, but not more likely to be tested in church-based VCT sites ( $21 \%$ versus $18 \% ; P=0.163) .{ }^{23}$ In a recent randomized trial involving 300 pregnant women during their first antenatal clinic visit in Kenya, visiting pregnant women and their partners at home resulted in HIV testing for $85 \%$ of male partners compared to $36 \%$ in the clinic-based male partner testing arm. ${ }^{24}$ In this study, women did not report harmful effects of male testing on relationship status. In addition, a large number $(n=29)$ of HIV discordant couples were identified in which the woman was HIV-infected and the man HIV-uninfected, or the man was HIV-infected and the women HIV-uninfected, thus providing potential in preventing new heterosexual and vertical HIV infections during pregnancy.

\section{Male involvement in PMTCT when the pregnant woman is HIV infected}

According to the UNAIDS 2013 Global AIDS Epidemic Report, more than $70 \%$ of the estimated 35 million people living with HIV and about 2.3 million who acquired new HIV infections globally in 2012 were in sub-Saharan Africa where women remain disproportionately affected. ${ }^{25}$ Although the HIV prevalence among young people declined by $42 \%$ between 2001 and 2012, young women aged 15-24 years remain twice as likely to acquire HIV compared to men in the same age group. The majority of PMTCT interventions, including increasing male partner involvement, have focused on delivery of a comprehensive PMTCT package to these HIV-infected women of reproductive age, as per WHO Prong 3 (Figure 1). Involving men at this juncture is critical because suboptimal use of maternal or infant antiretrovirals is frequently due to lack of male partner support and fear of abandonment or violence if the partner were to learn about the woman's HIV status. ${ }^{5}$

Indeed, several studies have demonstrated that partner support improves uptake and adherence to specific interventions. Initial studies conducted among HIV-infected pregnant women in Kenya showed that HIV-infected mothers whose male partners attended antenatal clinics and underwent couple HIV counseling and testing were three times as likely to report uptake of single dose nevirapine at delivery. ${ }^{8,13}$ Involving male partners of HIV-infected women was also associated with improved uptake of PMTCT interventions in Malawi, as well as enhanced HIV-free survival among children. ${ }^{22}$ Improved HIV-free survival among children was also reported in a Kenyan study that evaluated mother-infant pairs in which the father attended versus did not attend the antenatal clinic to participate in HTC. ${ }^{5}$ In this cohort of 535 pregnant HIV-infected women, 456 reported being in a relationship and, of these, $31 \%$ presented with their partners. Compared to children born to women whose male partners attended clinic, those children whose mothers were 
not accompanied by partners had a nearly two-fold greater risk of HIV infection or death. As more effective PMTCT protocols are adopted, male partner involvement may also increase women's uptake and adherence to more complex, life-long antiretroviral regimens as now recommended by the WHO as part of Option B Plus. In this Option all HIV infected pregnant or breastfeeding women are initiated on lifelong antiretroviral therapy irrespective of their CD4 count level or WHO stage. ${ }^{26}$ Research in this area will be important to determine benefits, as well as potential harms, and to define strategies that are feasible and cost effective.

It is also important to consider other ways in which male involvement may contribute to reducing MTCT following the WHO recommended four-prong approach (Figure 1). For example, integrating contraceptive services into PMTCT programs is important to prevent unintended pregnancies among HIV-infected women and prevent new pediatric HIV infections. ${ }^{27,28} \mathrm{~A}$ recent study in western Kenya found high unmet need for family planning with almost $60 \%$ of pregnancies reported as unintended, and a large proportion of women attributing this to lack of spousal support. ${ }^{29}$ Facility delivery and delivery with a skilled birth attendant are among other interventions that reduce overall maternal and neonatal morbidity and mortality and may be enhanced by engaging the male partner. In one study in Western Kenya, male par- ticipation in ANC was associated with skilled attendance at delivery irrespective of HIV status. ${ }^{30} \mathrm{~A}$ randomized clinical trial is currently underway to assess whether male partner involvement may increase the proportion of HIV-infected women who undergo skilled delivery, use dual contraception postpartum, and practice exclusive breastfeeding (Clinicaltrials.gov NCT01784783). ${ }^{31}$ Results of this investigation and others will be important for defining the scale and scope of beneficial outcomes with male involvement.

\section{Identifying HIV-discordant couples in the antenatal and postpartum setting}

In low resource settings, most women attend antenatal clinic at least once during pregnancy, undergo routine opt-out testing, and learn their HIV status. Due to low male partner testing, HIV status of male partners is often not known throughout the pregnancy and postpartum period. Consequently, HIVuninfected pregnant and breastfeeding women remain at risk of acute HIV infection because their male partner may be chronically or acutely infected with HIV yet be unaware of their status. ${ }^{12,32}$ As noted above, recent studies have shown high rates of maternal seroconversion during pregnancy and breastfeeding, and these acutely infected women have exceptionally high viral loads, leading to MTCT rates that are several times

Table I Outcomes associated with male partner HIV testing and engagement in PMTCT programs

\begin{tabular}{|c|c|c|c|}
\hline Study & Country & Study design/study population & Study outcomes \\
\hline Aluisio et $\mathrm{al}^{5}$ & Kenya & $\begin{array}{l}\text { Prospective cohort } / 456 \\
\text { HIV-infected pregnant women }\end{array}$ & $\begin{array}{l}\text { - Increased uptake of formula feeding and ART among } \\
\text { HIV-infected mothers when partners presented to clinic } \\
\text { - Decreased mortality among HIV-uninfected infants when } \\
\text { partners tested at presentation to clinic } \\
\text { - Decreased mother-to-child HIV transmission when } \\
\text { partners presented to clinic }\end{array}$ \\
\hline Farquhar et $\mathrm{al}^{8}$ & Kenya & $\begin{array}{l}\text { Prospective cohort } / 2,836 \text { pregnant } \\
\text { women; } 308 \text { male partners }\end{array}$ & $\begin{array}{l}\text { - Increased uptake of nevirapine with couple counseling } \\
\text { - Increased adherence to exclusive breastfeeding with } \\
\text { couple counseling } \\
\text { - Increased uptake of condom use with couple counseling }\end{array}$ \\
\hline Farquhar et $\mathrm{al}^{13}$ & Kenya & $\begin{array}{l}\text { Prospective cohort/I } 72 \\
\text { HIV-infected pregnant women }\end{array}$ & $\begin{array}{l}\text { - Increased likelihood of adhering to recommended } \\
\text { exclusive breastfeeding behaviors, such as formula feeding } \\
\text { - Increased uptake of ART among HIV-infected mothers }\end{array}$ \\
\hline Kalembo et $\mathrm{al}^{22}$ & Malawi & $\begin{array}{l}\text { Retrospective cohort/476 } \\
\text { HIV-infected pregnant women }\end{array}$ & $\begin{array}{l}\text { - Increased uptake of condom use by five-fold } \\
\text { - Increased likelihood of delivering babies at hospitals }\end{array}$ \\
\hline Mangeni et $\mathrm{al}^{30}$ & Kenya & Prospective cohort/730 couples & $\begin{array}{l}\text { - Increased utilization of skilled attendance at delivery } \\
\text { irrespective of HIV status by two-fold }\end{array}$ \\
\hline Rosenberg et $\mathrm{al}^{36}$ & South Africa & $\begin{array}{l}\text { Prospective cohort/508 HIV-infected } \\
\text { individuals in HIV-discordant couples }\end{array}$ & $\begin{array}{l}\text { - Decreased unprotected sex } \\
\text { - Increased uptake of condom use and dual contraception }\end{array}$ \\
\hline Peltzer et $\mathrm{al}^{48}$ & South Africa & $\begin{array}{l}\text { Prospective cohort/746 HIV-I } \\
\text { seropositive pregnant and } \\
\text { postnatal women }\end{array}$ & $\begin{array}{l}\text { - Disclosure of maternal HIV status to the male partners } \\
\text { increased maternal AZT adherence. } \\
\text { - Male involvement increased both maternal and infant } \\
\text { adherence to nevirapine. }\end{array}$ \\
\hline
\end{tabular}

Abbreviations: ART, antiretroviral therapy; AZT, zidovudine; HIV, human immunodeficiency virus; PMTCT, prevention of mother-to-child HIV transmission. 
greater than those among chronically infected women. ${ }^{33,34}$ As programs become more successful in diagnosing and providing prophylaxis for or treating HIV-infected women at their first antenatal visit, these acute maternal infections threaten to reduce the impact of PMTCT interventions and greatly hinder progress toward virtual elimination of HIV.

In high HIV burden settings, the prevalence of HIV discordance remains high with nearly half of HIV-infected individuals being in HIV-discordant relationships. In a recent randomized clinical trial in Kenya, $16 \%$ of more than 300 pregnant women tested with their male partners were in HIV-discordant relationships. ${ }^{24}$ Importantly, not only does pregnancy appear to place HIV-uninfected women at higher risk of acquiring HIV, but HIV-infected women who are pregnant may also be more likely to transmit HIV. In a multisite HIV-discordant-couples study involving 3,321 couples, there were 2,236 HIV-uninfected men in stable relationships, and male partners had a two-fold greater HIV incidence when their partners were pregnant versus not pregnant. ${ }^{35}$ Knowledge that a couple is HIV-discordant provides an opportunity for HIV prevention strategies, including treatment of the HIV-infected partner as prevention and preexposure prophylaxis for the HIV-uninfected partner. Other strategies to reduce heterosexual transmission, including condom use and dual contraception uptake, are also likely to increase when male partners are tested and both members of a couple learn their status. ${ }^{36}$ For these reasons, couple HIV counseling and testing, in which couples undergo rapid HIV testing simultaneously and are informed of their HIV status when together, should be considered the optimal strategy for HIV testing during pregnancy because it protects all parties. ${ }^{37,38}$

HIV-discordant couples who want to get pregnant face additional challenges trying to balance safe sexual activity with their desire for a family. While most strategies target the man after a woman is pregnant, by involving men at an early stage, there may be more support for safe conception techniques among HIV-discordant couples. For example, couples could decide together to access pre-exposure prophylaxis with or without timed intercourse, sperm washing for either intrauterine insemination, in vitro fertilization, or intracytoplasmic sperm injection, and intrauterine insemination. ${ }^{39}$

\section{Partner involvement in enhancing uptake of treatment and linkage to care}

In resource-rich and resource-poor settings, HIV-infected individuals often present when in advanced stage of disease for care and treatment due to late diagnosis or poor linkage to care. During pregnancy, high antenatal clinic attendance and opt-out HTC provide the opportunity for early diagnosis and initiation of antiretroviral therapy (ART) among pregnant HIV-infected women. Currently, WHO recommends initiation of lifelong ART, also known as Option B Plus, for all HIV-infected pregnant women. Uptake of PMTCT interventions including Option B Plus is likely to be enhanced through male involvement and, therefore, maternal access of HIV care and treatment is also likely to be increased when male partners are engaged. Partner notification, HIV testing, and other forms of male involvement may also augment a woman's adherence to ART long-term. While there are currently no published data, this may change as Option B Plus is scaled up across sub-Saharan Africa.

\section{Male partner health benefits}

There are also discrete health benefits for male partners because men tend to have poor health-seeking behavior, which often results in late HIV diagnosis, presentation with advanced HIV disease, and consequently high HIV-related morbidity and mortality. A systematic review of HIV care and treatment found that men in sub-Saharan Africa were more likely to be lost to follow-up and less likely to be retained in care when compared to women registered in the same clinics. ${ }^{40,41}$ Thus, another advantage of male partner HIV testing during pregnancy is that it will identify HIV-infected men earlier and provide opportunities for linkages to HIV treatment and care. Additionally, men whose female partners are aware of their HIV status may be more likely to access care due to increased partner support.

\section{Determinants and barriers to male partner testing}

Pregnant women and their partners cite multiple barriers to male partner involvement in PMTCT, the majority of which can be categorized as sociocultural or health systems barriers. For example, men in sub-Saharan Africa do not expect maternal and child health clinic facilities to be male friendly and are therefore reluctant to present for services at antenatal clinics ${ }^{42,43}$ Other barriers to clinic-based testing include lack of awareness of the role of male partners in antenatal care, economic limitations (eg, time off work, costs of transport), multiple and concurrent sexual partnerships, inadequate space in the facility, and negative staff attitudes. ${ }^{42,44}$ Although sociocultural factors have been accepted as the major barrier to antenatal male partner testing, facility factors can hinder efforts to overcome traditional practices and encourage male involvement. Improving facility and staff attitudes toward male involvement has the potential to improve service delivery to all pregnant women; however, care must be taken to avoid discriminating against 
unaccompanied women who are either single or in unstable relationships.

Stigma and fear of disclosure are also significant barriers to involvement of men in PMTCT. Both men and women may experience fear or HIV-associated stigma resulting in reluctance to share HIV status with a sexual partner. Despite this concern, recent studies have shown that male partner testing can enhance communication by facilitating mutual disclosure of HIV status. In these studies, women were more likely to be accepted and supported by their male partners after couple counseling and testing, leading to improved access to care and adherence to treatment. ${ }^{45-47}$ A recent study in South Africa also found that women who disclosed their HIV status actually had less discrimination and better maternal and pediatric adherence to antiretrovirals. ${ }^{48}$

\section{Male involvement in PMTCT when the woman is HIV-uninfected}

Despite high HIV prevalence in many parts of Africa, the majority of young women in areas with generalized epidemics are HIV-uninfected. When pregnant and breastfeeding, these young women are at high risk of acquiring HIV and subsequently transmitting HIV to their infants. ${ }^{49-51}$ One Kenyan study that evaluated women who were HIV-uninfected during their first antenatal visit calculated an HIV incidence of 6.8 per 100 woman-years at 6 weeks postpartum, ${ }^{52}$ and several other recent studies report HIV-1 incidences ranging from 1.3 to 10.7 per 100 women-years during the pregnancy and breastfeeding period. ${ }^{49-51}$ Engaging male partners of HIV-uninfected women through couple HTC and counseling on risk reduction may contain this high HIV incidence during the pregnancy and breastfeeding period, and will potentially be documented in future studies or programs designed to assess this.

\section{Non-HIV related benefits, including other aspects of maternal and child health}

Male partner involvement may have other reproductive and general health benefits beyond enhancing HIV testing, prevention, and treatment efforts. In Nepal, a randomized trial of 442 women seeking prenatal care found that women whose husbands attended antenatal health education sessions were more likely to retain knowledge on health education, return for a postnatal visit, identify pregnancy complications, report birth preparedness, and consider family planning methods than those randomized to sessions not including the spouse..$^{53,54}$ In another randomized trial in Uganda among 5,094 women, notifying the male partner of results was associated with a three-fold increase in the likelihood that women referred for colposcopy would return for care. ${ }^{55}$ In Malawi, male engagement during contraception counseling improved communication between partners and contraceptive uptake. ${ }^{56,57}$ Additionally, analysis of the Kenya demographic and health survey data showed that pregnant women whose male partners attended antenatal clinic had a two-fold increase in skilled attendance at delivery compared to those who were not accompanied by their male partners. ${ }^{30}$ Finally, male partner education and engagement on infant breastfeeding has been associated with improvements in initiation, exclusivity, and continuation of breastfeeding, even in non-HIV-infected populations, ${ }^{58}$ and spousal support has been associated with better infant immunization practices in some parts of sub-Saharan Africa. ${ }^{59}$ Based on these encouraging results in non-HIV settings, additional programs and studies should be promoted that will implement and evaluate benefits of male involvement in PMTCT that extend beyond HIV prevention.

\section{Limitations of this review}

Many of the studies found on male partner involvement were conducted without incorporating a comprehensive approach to PMTCT or assessing outcomes beyond vertical HIV transmission. Additionally, the majority had short-term follow-up to address long-term outcomes and were primarily concerned with clinic-based approaches to male involvement.

\section{Conclusion}

In this review, we showed compelling evidence that male partner involvement plays a critical role in PMTCT in low resource high HIV-burden settings. Evidence is also accumulating that couple counseling and HIV testing during pregnancy is not significantly associated with adverse outcomes. ${ }^{24}$ While male involvement has been primarily focused on Prong 3 of PMTCT when the woman is HIV-infected, addressing other prongs and engaging partners of HIV-uninfected women is essential to achieving virtual elimination of MTCT. Male involvement has the potential to improve uptake of combination HIV-prevention interventions among HIV-discordant couples, including treatment as prevention and preexposure prophylaxis, which would prevent both men and women of reproductive age from acquiring HIV. Engaging men during the antenatal and postpartum period may also benefit women and children more generally by promoting safe deliveries, exclusive breastfeeding, family planning, and other core components of maternal child health, as well as benefiting men through early HIV diagnosis and linkage to care. To overcome barriers to male involvement, home-based couple testing and education during pregnancy has been introduced in some settings and shown to be acceptable and feasible. 
Determining cost-effective ways to implement home-based couple HCT will be critical for this to be successful. Other new HIV testing options for couples, such as HIV self-testing using saliva-based kits, should also be considered in high HIV burden settings, but will need careful attention to potential social harms. Assessing these established and innovative interventions in those communities most affected by the epidemic is an important next step on the path toward scaling up and implementation of effective strategies at the national and regional level.

\section{Acknowledgments}

AO received support from the Fogarty International Center of the US National Institutes of Health $(\mathrm{NIH})$ grant number D43 TW000007, and CF received support from NIH award number K24 AI087399. The content is solely the responsibility of the authors and does not necessarily represent the official views of the NIH.

\section{Author contributions}

$\mathrm{AO}$ and $\mathrm{CF}$ wrote the initial manuscript draft and $\mathrm{HH}$ created the figures and tables. All authors were responsible for contributions to conception and design, acquisition of data, or analysis and interpretation of data, and revised and approved the final draft.

\section{Disclosure}

The authors report no conflicts of interest in this work.

\section{References}

1. 2013 Progress Report on the Global Plan towards the Elimination of New HIV Infections among Children by 2015 and Keeping Their Mothers Alive [webpage on the Internet]. Geneva: UN Joint Programme on HIV/AIDS (UNAIDS); 2013. Available from: http://www.refworld.org/ docid/5208eb834.html. Accessed March 10, 2014.

2. Strategic Approaches to the Prevention of HIV Infection in Infants: Reporting on a WHO Meeting: Morges, Switzerland, March 20-22, 2002 [webpage on the Internet]. Geneva: World Health Organization; 2003. Available from: http://www.who.int/hiv/pub/mtct/en/. Accessed October 19, 2013.

3. The State of the World's Children 2007: Women and children, the double dividend of gender equality [webpage on the Internet]. New York: United Nations Children's Fund (UNICEF); 2007. Available from: http://www. unicef.org/sowc07/. Accessed March 10, 2014.

4. Akarro RRJ, Deonisia M, Sichona FJ. An Evaluation of Male Involvement on the Programme for PMTCT of HIVIAIDS: A Case Study of Ilala Municipal in Dares Salam, Tanzania. Arts and Social Sciences Journal; 2011. Available from: http://astonjournals.com/manuscripts/Vol2011/ ASSJ-20_Vol2011.pdf. 2011. Accessed March 10, 2014.

5. Aluisio A, Richardson BA, Bosire R, John-Stewart G, Mbori-Ngacha D, Farquhar C. Male antenatal attendance and HIV testing are associated with decreased infant HIV infection and increased HIV-free survival. J Acquir Immune Defic Syndr. 2011;56(1):76-82.

6. Byamugisha R, Tumwine JK, Semiyaga N, Tylleskär T. Determinants of male involvement in the prevention of mother-to-child transmission of HIV programme in Eastern Uganda: a cross-sectional survey. Reprod Health. 2010;7:12.
7. Mirkuzie AH, Hinderaker SG, Mørkve O. Promising outcomes of a national programme for the prevention of mother-to-child HIV transmission in Addis Ababa: a retrospective study. BMC Health Serv Res. 2010;10:267.

8. Farquhar C, Kiarie JN, Richardson BA, et al. Antenatal couple counseling increases uptake of interventions to prevent HIV-1 transmission. J Acquir Immune Defic Syndr. 2004;37(5):1620-1626.

9. Mohlala BK, Boily MC, Gregson S. The forgotten half of the equation: randomized controlled trial of a male invitation to attend couple voluntary counselling and testing. AIDS. 2011;25(12):1535-1541.

10. Orne-Gliemann J, Tchendjou PT, Miric M, et al. Couple-oriented prenatal HIV counseling for HIV primary prevention: an acceptability study. BMC Public Health. 2010;10:197.

11. Byamugisha R, Åstrøm AN, Ndeezi G, Karamagi CA, Tylleskär T, Tumwine JK. Male partner antenatal attendance and HIV testing in eastern Uganda: a randomized facility-based intervention trial. $J$ Int AIDS Soc. 2011;14:43.

12. Msuya SE, Mbizvo EM, Hussain A, Uriyo J, Sam NE, Stray-Pedersen B. Low male partner participation in antenatal HIV counselling and testing in northern Tanzania: implications for preventive programs. AIDS Care. 2008;20(6):700-709.

13. Farquhar C, Mbori-Ngacha DA, Bosire RK, Nduati RW, Kreiss JK, John GC. Partner notification by HIV-1 seropositive pregnant women: association with infant feeding decisions. AIDS. 2001;15(6):815-817.

14. Katz DA, Kiarie JN, John-Stewart GC, Richardson BA, John FN, Farquhar C. Male perspectives on incorporating men into antenatal HIV counseling and testing. PLoS One. 2009;4(11):e7602.

15. Becker S, Mlay R, Schwandt HM, Lyamuya E. Comparing couples' and individual voluntary counseling and testing for HIV at antenatal clinics in Tanzania: a randomized trial. AIDS Behav. 2010;14(3):558-566.

16. Kim LH, Arinaitwe E, Nzarubara B, et al. Acceptability and feasibility of serial HIV antibody testing during pregnancy/postpartum and male partner testing in Tororo, Uganda. AIDS Care. 2014;26(3):360-363.

17. Chandisarewa W, Stranix-Chibanda L, Chirapa E, et al. Routine offer of antenatal HIV testing ("opt-out" approach) to prevent mother-to-child transmission of HIV in urban Zimbabwe. Bull World Health Organ. 2007;85(11):843-850.

18. Aarnio P, Olsson P, Chimbiri A, Kulmala T. Male involvement in antenatal HIV counseling and testing: exploring men's perceptions in rural Malawi. AIDS Care. 2009;21(12):1537-1546.

19. Semrau K, Kuhn L, Vwalika C, et al. Women in couples antenatal HIV counseling and testing are not more likely to report adverse social events. AIDS. 2005;19(6):603-609.

20. Orne-Gliemann J, Balestre E, Tchendjou P, et al. Increasing HIV testing among male partners. AIDS. 2013;27(7):1167-1177.

21. Byamugisha R, Tylleskär T, Kagawa MN, Onyango S, Karamagi CA, Tumwine JK. Dramatic and sustained increase in HIV-testing rates among antenatal attendees in Eastern Uganda after a policy change from voluntary counselling and testing to routine counselling and testing for HIV: a retrospective analysis of hospital records, 2002-2009. BMC Health Serv Res. 2010;10:290.

22. Kalembo FW, Zgambo M, Mulaga AN, Yukai D, Ahmed NI. Association between male partner involvement and the uptake of prevention of motherto-child transmission of HIV (PMTCT) interventions in Mwanza district, Malawi: a retrospective cohort study. PLoS One. 2013;8(6):e66517.

23. Ditekemena J, Matendo R, Koole O, et al. Male partner voluntary counselling and testing associated with the antenatal services in Kinshasa, Democratic Republic of Congo: a randomized controlled trial. Int J STD AIDS. 2011;22(3):165-170.

24. Osoti AO, John-Stewart G, Kiarie J, et al. Home visits during pregnancy enhance male partner HIV counselling and testing in Kenya: a randomized clinical trial. AIDS. 2014;28(1):95-103.

25. UNAIDS. Global Report: UNAIDS Report on the Global AIDS Epidemic 2013. Geneva: UN Joint Programme on HIV/AIDS (UNAIDS); 2013. Available from: http://www.unaids.org/en/media/ unaids/contentassets/documents/epidemiology/2013/gr2013/UNAIDS_ Global_Report_2013_en.pdf. Accessed, November 29, 2013. 
26. Centers for Disease Control and Prevention. Webpage on Internet. Impact of an innovative approach to prevent mother-to-child transmission of HIV - Malawi, July 2011-September 2012. Morb Mortal Wkly Rep (MMWR). Available from: http://www.cdc.gov/mmwr/preview/ mmwrhtml/mm6208a3.htm. Accessed March 24, 2014.

27. Wilcher R, Petruney T, Cates W. The role of family planning in elimination of new pediatric HIV infection. Curr Opin HIV AIDS. 2013; 8(5):490-497.

28. Wilcher R, Hoke T, Adamchak SE, Cates W. Integration of family planning into HIV services: a synthesis of recent evidence. AIDS. 2013; 27 Suppl 1:S65-S75.

29. Akelo V, Girde S, Borkowf CB, et al. Attitudes toward family planning among HIV-positive pregnant women enrolled in a prevention of mother-to-child transmission study in Kisumu, Kenya. PLoS One. 2013;8(8):e66593.

30. Mangeni M, Mbugua, Mukthar. Male involvement in maternal health care as a determinant of utilization of skilled birth attendants in Kenya [webpage on the Internet]. Claverton: MEASURE DHS; 2013. Available from: http://www.measuredhs.com/publications/publication-wp93working-papers.cfm. Accessed, November 29, 2013.

31. ClinicalTrials.Gov. Home-based Partner Education and Testing (HOPE) Study. Available from: http://clinicaltrials.gov/show/NCT01784783. NCT identifier: NCT01784783. Accessed March 24, 2103.

32. Auvinen J, Suominen T, Välimäki M. Male participation and prevention of human immunodeficiency virus (HIV) mother-to-child transmission in Africa. Psychol Health Med. 2010;15(3):288-313.

33. Palasanthiran P, Ziegler JB, Stewart GJ, et al. Breast-feeding during primary maternal human immunodeficiency virus infection and risk of transmission from mother to infant. J Infect Dis. 1993;167(2):441-444.

34. Cao Y, Krogstad P, Korber BT, et al. Maternal HIV-1 viral load and vertical transmission of infection: the Ariel Project for the prevention of HIV transmission from mother to infant. Nat Med. 1997;3(5):549-552.

35. Mugo NR, Heffron R, Donnell D, et al. Increased risk of HIV-1 transmission in pregnancy: a prospective study among African HIV-1serodiscordant couples. AIDS. 2011;25(15):1887-1895.

36. Rosenberg NE, Pettifor AE, De Bruyn G, et al. HIV testing and counseling leads to immediate consistent condom use among South African stable HIV-discordant couples. J Acquir Immune Defic Syndr. 2013;62(2):226-233.

37. Baeten JM, Donnell D, Ndase P, et al. Antiretroviral prophylaxis for HIV prevention in heterosexual men and women. $N$ Engl $J$ Med. 2012;367(5):399-410.

38. Cohen MS, Chen YQ, McCauley M, et al. Prevention of HIV-1 infection with early antiretroviral therapy. N Engl J Med. 2011;365(6):493-505.

39. Lampe MA, Smith DK, Anderson GJ, Edwards AE, Nesheim SR. Achieving safe conception in HIV-discordant couples: the potential role of oral preexposure prophylaxis (PrEP) in the United States. Am J Obstet Gynecol. 2011;204(6):488.

40. Fox MP, Rosen S. Patient retention in antiretroviral therapy programs up to three years on treatment in sub-Saharan Africa, 2007-2009: systematic review. Trop Med Int Health. 2010;15 Suppl 1:1-15.

41. Rosen S, Fox MP. Retention in HIV care between testing and treatment in sub-Saharan Africa: a systematic review. PLoS Med. 2011;8(7):e1001056.

42. Nkuoh GN, Meyer DJ, Tih PM, Nkfusai J. Barriers to men's participation in antenatal and prevention of mother-to-child HIV transmission care in Cameroon, Africa. J Midwifery Womens Health. 2010;55(4):363-369.

Research and Reports in Neonatology

\section{Publish your work in this journal}

Research and Reports in Neonatology is an international, peer-reviewed, open access journal publishing original research, reports, editorials, reviews and commentaries on neonatal health. The manuscript management system is completely online and includes a very quick and fair
43. Bajunirwe F, Muzoora M. Barriers to the implementation of programs for the prevention of mother-to-child transmission of HIV: a cross-sectional survey in rural and urban Uganda. AIDS Res Ther. 2005;2:10.

44. Kebaabetswe PM. Barriers to participation in the prevention of motherto-child HIV transmission program in Gaborone, Botswana a qualitative approach. AIDS Care. 2007;19(3):355-360.

45. Mayer KH. Introduction: Linkage, engagement, and retention in HIV care: essential for optimal individual- and community-level outcomes in the era of highly active antiretroviral therapy. Clin Infect Dis. 2011; 52 Suppl 2:S205-S207.

46. Mepham S, Zondi Z, Mbuyazi A, Mkhwanazi N, Newell ML. Challenges in PMTCT antiretroviral adherence in northern KwaZulu-Natal, South Africa. AIDS Care. 2011;23(6):741-747.

47. Duff P, Kipp W, Wild TC, Rubaale T, Okech-Ojony J. Barriers to accessing highly active antiretroviral therapy by HIV-positive women attending an antenatal clinic in a regional hospital in western Uganda. J Int AIDS Soc. 2010;13:37.

48. Peltzer K, Sikwane E, Majaja M. Factors associated with short-course antiretroviral prophylaxis (dual therapy) adherence for PMTCT in Nkangala district, South Africa. Acta Paediatr. 2011;100(9):1253-1257.

49. Leroy V, Van de Perre P, Lepage P, et al. Seroincidence of HIV-1 infection in African women of reproductive age: a prospective cohort study in Kigali, Rwanda, 1988-1992. AIDS. 1994;8(7):983-986.

50. Gray RH, Li X, Kigozi G, et al. Increased risk of incident HIV during pregnancy in Rakai, Uganda: a prospective study. Lancet. 2005;366(9492):1182-1188.

51. Munjoma MW, Mhlanga FG, Mapingure MP, et al. The incidence of HIV among women recruited during late pregnancy and followed up for six years after childbirth in Zimbabwe. BMC Public Health. 2010;10:668.

52. Kinuthia J, Kiarie JN, Farquhar C, et al. Cofactors for HIV-1 incidence during pregnancy and postpartum period. Curr HIV Res. 2010;8(7): $510-514$.

53. Mullany BC, Becker S, Hindin MJ. The impact of including husbands in antenatal health education services on maternal health practices in urban Nepal: results from a randomized controlled trial. Health Educ Res. 2007;22(2):166-176.

54. Mullany BC, Lakhey B, Shrestha D, Hindin MJ, Becker S. Impact of husbands' participation in antenatal health education services on maternal health knowledge. JNMA J Nepal Med Assoc. 2009;48(173):28-34.

55. Mutyaba T, Mirembe F, Sandin S, Weiderpass E. Male partner involvement in reducing loss to follow-up after cervical cancer screening in Uganda. Int J Gynaecol Obstet. 2009;107(2):103-106.

56. Shattuck D, Kerner B, Gilles K, Hartmann M, Ng'ombe T, Guest G. Encouraging contraceptive uptake by motivating men to communicate about family planning: the Malawi Male Motivator project. Am J Public Health. 2011;101(6):1089-1095.

57. Hartmann M, Gilles K, Shattuck D, Kerner B, Guest G. Changes in couples' communication as a result of a male-involvement family planning intervention. J Health Commun. 2012;17(7):802-819.

58. Mitchell-Box KM, Braun KL. Impact of male-partner-focused interventions on breastfeeding initiation, exclusivity, and continuation. J Hum Lact. 2013;29(4):473-479.

59. Babirye JN, Rutebemberwa E, Kiguli J, Wamani H, Nuwaha F, Engebretsen IM. More support for mothers: a qualitative study on factors affecting immunisation behaviour in Kampala, Uganda. $B M C$ Public Health. 2011;11:723.

peer-review system. Visit http://www.dovepress.com/testimonials.php to read real quotes from published authors. 